\title{
A FISH approach to defining the extent and possible clinical significance of deletions at the WAGR locus
}

\author{
John A Crolla, John E Cawdery, Christine A Oley, Ian D Young, Jonathon Gray, \\ Judy Fantes, Veronica van Heyningen
}

Wessex Regional Genetics Laboratory, Salisbury District Hospital, Salisbury, Wiltshire SP2 8BJ, UK J A Crolla

Royal Gwent Hospital, Cardiff Road, Newport, Gwent NP9 2UB, UK

J E Cawdery

\section{Northern Region}

Genetics Service, 19/20

Claremont Place,

Newcastle upon Tyne

NE2 4AA, UK

C A Oley*

\section{Clinical Genetics}

Service, City Hospital, Nottingham NG5 1PB, UK

I D Young

Institute of Medical Genetics, University Hospital of Wales, Heath Park, Cardiff CF4 4XW, UK

J Gray

MRC Human Genetics Unit, Western General Hospital, Crewe Road, Edinburgh EH4 2XU, UK

$J$ Fantes

$\mathrm{V}$ van Heyningen

Correspondence to: Dr Crolla.

* Present address: Queensland Clinica Genetics Service, Royal Children's Hospital, Herston Queensland 4029, Australia.

Received 26 June 1996 Revised version accepted for publication 31 October 1996

\begin{abstract}
Nineteen patients were analysed by fluorescence in situ hybridisation (FISH) with selected $11 \mathrm{p} 13$ markers. They were examined because they had either isolated sporadic or familial aniridia, or aniridia with one or more of the WAGR (Wilms' tumour, aniridia, genital anomalies, and mental retardation) syndrome anomalies. The FISH markers from distal 11p13 were cosmids FO2121, PAX6 (aniridia), D11S324, and WT1 (Wilms' tumour predisposition). Two of the patients with isolated aniridia were abnormal, one with an apparently balanced reciprocal $7 ; 11$ translocation and an 11 p13 breakpoint, which by FISH was shown to be $\sim 30 \mathrm{~kb}$ distal to the aniridia (PAX6) gene, and the other had a submicroscopic deletion involving part of PAX6 that extended distally for $\sim 245 \mathrm{~kb}$. Two patients with aniridia together with other WAGR malformations had deletions involving all four cosmids. One case with aniridia associated with developmental and growth delay had a deletion including FO2121 and PAX6 but not D11S324 and WT1, while in a further case the deletion included all four test cosmids. These studies show that a combined conventional and molecular cytogenetic approach to patients presenting with aniridia is a useful method for differentiating between those with deletions extending into and including WT1 and therefore between those with high and low risks of developing Wilms' tumour.

(F Med Genet 1997;34:207-212)
\end{abstract}

Keywords: FISH; WAGR locus.

The location of genes responsible for the clinical features of the WAGR syndrome (Wilms' tumour, aniridia, genitourinary abnormalities, and mental retardation) was first suggested by the association of cytogenetically visible interstitial deletions of the short arm of chromosome 11 involving band $11 \mathrm{p}_{13^{12}}$ in patients presenting with one or more of the WAGR anomalies. Expression of these phenotypes, however, was noted to be variable even in patients with apparently identical deletions. ${ }^{13}$ From these early studies it was estimated that the overall risk for Wilms' tumour in sporadic and karyotypically normal aniridia patients was approximately $33 \%$, rising to $68 \%$ in aniridia patients with cytogenetically visible $11 \mathrm{p} 13$ deletions. ${ }^{45}$

Molecular studies have recently identified both a Wilms' tumour predisposition gene, WT $1,{ }^{67}$ and the human aniridia gene, PAX $6,{ }^{8}$ both of which map to an approximately $700 \mathrm{~kb}$ interval in distal $11 \mathrm{p} 13$. Mutations in PAX6, including deletions, have been identified in most but not all tested patients with either sporadic or familial aniridia. ${ }^{9-15}$ Studies using combined molecular techniques including Southern blotting, pulse field gel electrophoresis, and fluorescence in situ hybridisation (FISH) with probes from within or flanking the WAGR region have been used to define the proximal and distal breakpoints of both visible and submicroscopic deletions in patients with isolated aniridia or aniridia in association with the WAGR syndrome. ${ }^{12-14}{ }^{17}$ These studies have clearly shown that deletions including WT1 are correlated with significantly increased risk of Wilms' tumour development.

In this study we have used FISH in combination with four cosmid probes including both the human aniridia (PAX6) and Wilms' tumour predisposition (WT1) loci. These probes have been cloned from an approximately $800 \mathrm{~kb}$ region of distal $11 \mathrm{p} 13$. Our aim was to test whether FISH alone has the same sensitivity as other molecular methods for detecting and defining the extent of deletions, and hence their clinical significance, when applied to a series of patients presenting with isolated aniridia or aniridia with one or more features of the WAGR syndrome.

\section{The study population}

Recruitment of patients was achieved principally by publicising the availability of a diagnostic FISH service using WAGR cosmids (see below) in the Bulletin of the Clinical Genetics Society of the United Kingdom. Nineteen patients, who fall into three principal phenotypic groups, have so far been studied (table 1). The first group comprised 13 patients with isolated sporadic or familial aniridia. The two patients in the second group presented with aniridia together with one or more of the WAGR syndrome abnormalities whereas the third group contained four patients with sporadic aniridia in combination with anomalies other than those normally associated with the WAGR syndrome. 
Table 1 Patients by ascertainment

\begin{tabular}{|c|c|c|}
\hline Case No & $\begin{array}{l}\text { Phenotypic } \\
\text { group }\end{array}$ & Cytogenetic/FISH results (ISCN 1995) \\
\hline 1 & 1 & $46, \mathrm{XX}, \mathrm{t}(7 ; 11)(\mathrm{q} 31.2 ; \mathrm{p} 13)$.ish $(\mathrm{FO} 2121+; \mathrm{FAT} 5+, \mathrm{D} 11 \mathrm{~S} 324+, \mathrm{B} 2.1+)$ \\
\hline 2 & 1 & $46, \mathrm{XY}$.ish $11 \mathrm{p} 13(\mathrm{FO} 2121 \times 2, \mathrm{FAT} 5 \times 2, \mathrm{D} 11 \mathrm{~S} 324 \times 2, \mathrm{~B} 2.1 \times 2)$ \\
\hline 3 & 1 & $46, \mathrm{XY}$.ish $11 \mathrm{p} 13(\mathrm{FO} 2121 \times 2, \mathrm{FAT} 5 \times 2, \mathrm{D} 11 \mathrm{~S} 324 \times 2, \mathrm{~B} 2.1 \times 2)$ \\
\hline 4 & 1 & $46, \mathrm{XY}$.ish $11 \mathrm{p} 13(\mathrm{FO} 2121 \times 2, \mathrm{FAT} 5 \times 2, \mathrm{D} 11 \mathrm{~S} 324 \times 2, \mathrm{~B} 2.1 \times 2)$ \\
\hline 5 & 1 & 46,XY.ish $11 \mathrm{p} 13(\mathrm{FO} 2121 \times 2, \mathrm{FAT} 5 \times 2, \mathrm{D} 11 \mathrm{~S} 324 \times 2, \mathrm{~B} 2.1 \times 2)$ \\
\hline 6 & 1 & ish $11 \mathrm{p} 13(\text { FAT } 5 \times 2, \mathrm{D} 11 \mathrm{~S} 324 \times 2, \mathrm{~B} 2.1 \times 2)^{\star}$ \\
\hline 7 & 1 & ish $11 \mathrm{p} 13(\mathrm{FO} 2121 \times 2, \mathrm{FAT} 5 \times 2, \mathrm{D} 11 \mathrm{~S} 324 \times 2, \mathrm{~B} 2.1 \times 2)^{\star}$ \\
\hline 8 & 1 & ish $11 \mathrm{p} 13(\mathrm{FO} 2121 \times 2, \mathrm{FAT} 5 \times 2, \mathrm{D} 11 \mathrm{~S} 324 \times 2, \mathrm{~B} 2.1 \times 2)^{\star}$ \\
\hline 9 & 1 & ish $11 \mathrm{p} 13(\mathrm{FO} 2121 \times 2, \mathrm{FAT} 5 \times 2 \text {,D1 } 1 \mathrm{~S} 324 \times 2, \mathrm{~B} 2.1 \times 2)^{\star}$ \\
\hline 10 & 1 & ish $11 \mathrm{p} 13(\mathrm{FO} 2121 \times 2, \mathrm{FAT} 5 \times 2 \text {,D11S324×2,B2. } 1 \times 2)^{\star}$ \\
\hline 11 & 3 & 46,XY.ish $11 \mathrm{p} 13(\mathrm{FO} 2121 \times 2, \mathrm{FAT} 5 \times 2, \mathrm{D} 11 \mathrm{~S} 324 \times 2, \mathrm{~B} 2.1 \times 2)$ \\
\hline 12 & 3 & 46,XY.ish $11 \mathrm{p} 13(\mathrm{FO} 2121 \times 2, \mathrm{FAT} 5 \times 2, \mathrm{D} 11 \mathrm{~S} 324 \times 2, \mathrm{~B} 2.1 \times 2)$ \\
\hline 13 & 3 & $\begin{array}{l}\text { 46,XY,del(11)(p13;p15.1).ish } \\
\operatorname{del}(11)(\mathrm{p} 13 \mathrm{p} 13) \text { de novo(FO2121-,FAT5-,D11S324+,B2.1+) }\end{array}$ \\
\hline 14 & 2 & $\begin{array}{l}\text { 46,XY,del(11)(p13;p14.2)de novo.ish } \\
\operatorname{del}(11)(\mathrm{p} 13 \mathrm{p} 13)(\mathrm{FO} 2121-, \mathrm{FAT} 5-, \mathrm{D} 11 \mathrm{~S} 324-, \mathrm{B} 2.1-)\end{array}$ \\
\hline 15 & 3 & $\begin{array}{l}\text { 46,XX,del(11)(p11.2;p14.1)de novo.ish } \\
\operatorname{del}(11)(\mathrm{p} 13 \mathrm{p} 13)(\mathrm{FO} 2121-, \mathrm{FAT} 5-, \mathrm{D} 11 \mathrm{~S} 324-, \mathrm{B} 2.1-)\end{array}$ \\
\hline 16 & 2 & 46,XY.ish del(11)(p13p13)(FO2121-,FAT5-,D11S324-,B2.1)de novo \\
\hline 17 & 1 & ish $11 \mathrm{p} 13(\mathrm{FO} 2121 \times 2 \text {,FAT } 5 \times 2, \mathrm{D} 11 \mathrm{~S} 324 \times 2, \mathrm{~B} 2.1 \times 2)^{\star}$ \\
\hline 18 & 1 & ish $11 \mathrm{p} 13(\mathrm{FO} 2121 \times 2, \mathrm{FAT} 5 \times 2, \mathrm{D} 11 \mathrm{~S} 324 \times 2, \mathrm{~B} 2.1 \times 2)^{\star}$ \\
\hline 19 & 1 & 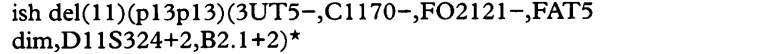 \\
\hline
\end{tabular}

*Patients reported with apparently normal karyotypes, therefore conventional studies not repeated.

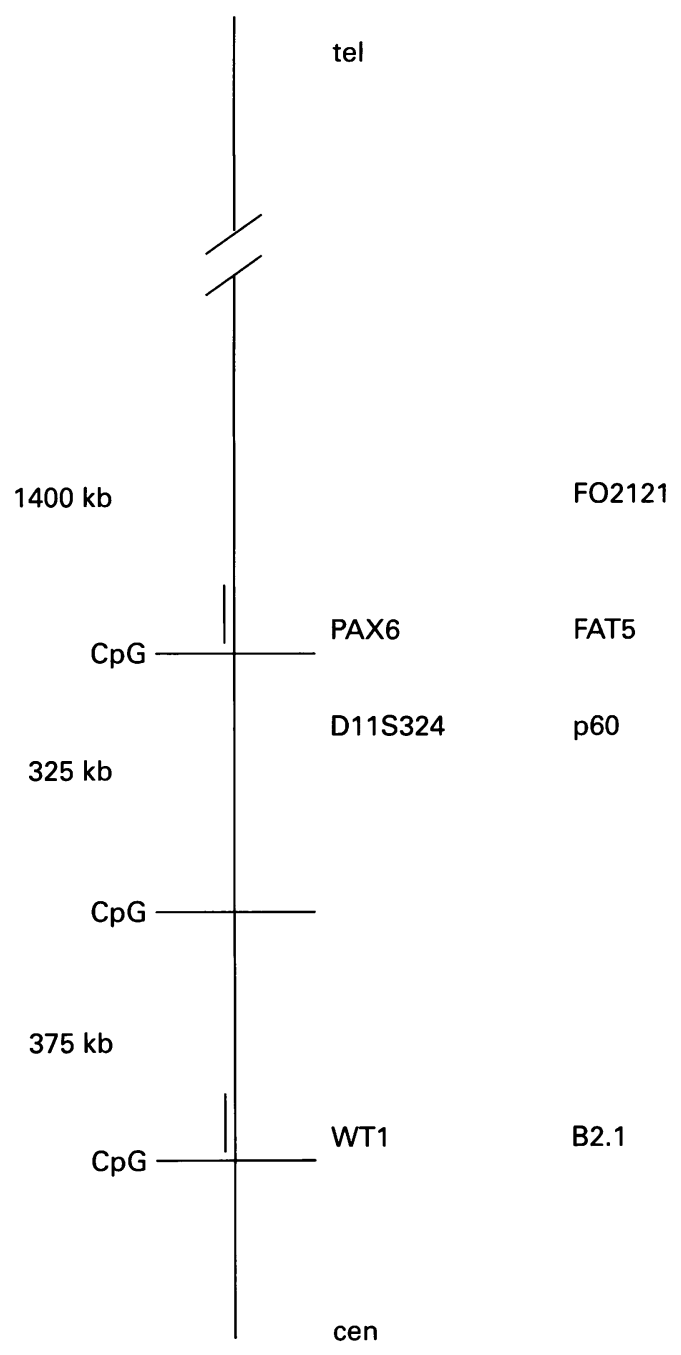

Figure 1 A map of distal 11p13 showing the positions of the probes used in the study.

UK) and examined using a Carl Zeiss Axioskop epifluorescent microscope fitted with Chroma Technology's Pinkel fluorescent No 83 filter series. Images were captured using a cooled CCD camera and the digitised data was analysed and visualised using "Smartcapture" software (Digital Scientific, Cambridge, UK); $11 \mathrm{p} 13$ specific cosmid signal was seen as red and the alphoid repeat as green (fig 2). A minimum of 10 metaphases were scored after hybridisation with each probe. With all four cosmids, signal was seen on both chromatids of all non-deleted homologues in $80 \%$ of metaphases, with the remaining cells showing signal on one chromatid on one or, more rarely, both normal homologues. Signal was not seen on deleted chromosomes. However, in case 19, of the 20 metaphases examined after hybridisation with FAT5, 10 showed normal signal distribution on one 11 , and a significantly smaller signal on the other (fig $2 \mathrm{D}$ ). In the remaining 10 cells, no signal was seen on the abnormal homologue.

\section{Clinical descriptions and results \\ CASE 1}

The details of this patient have been reported separately. ${ }^{16}$ More recent studies have shown that the $11 \mathrm{p} 13$ breakpoint disrupts cosmid using one layer of antidigoxigenin-TR The chromosomal DNA was counterstained with $0.05 \mathrm{mg} / \mathrm{ml}$ DAPI suspended in an antifade solution (Vectashield, Vector Labs, 

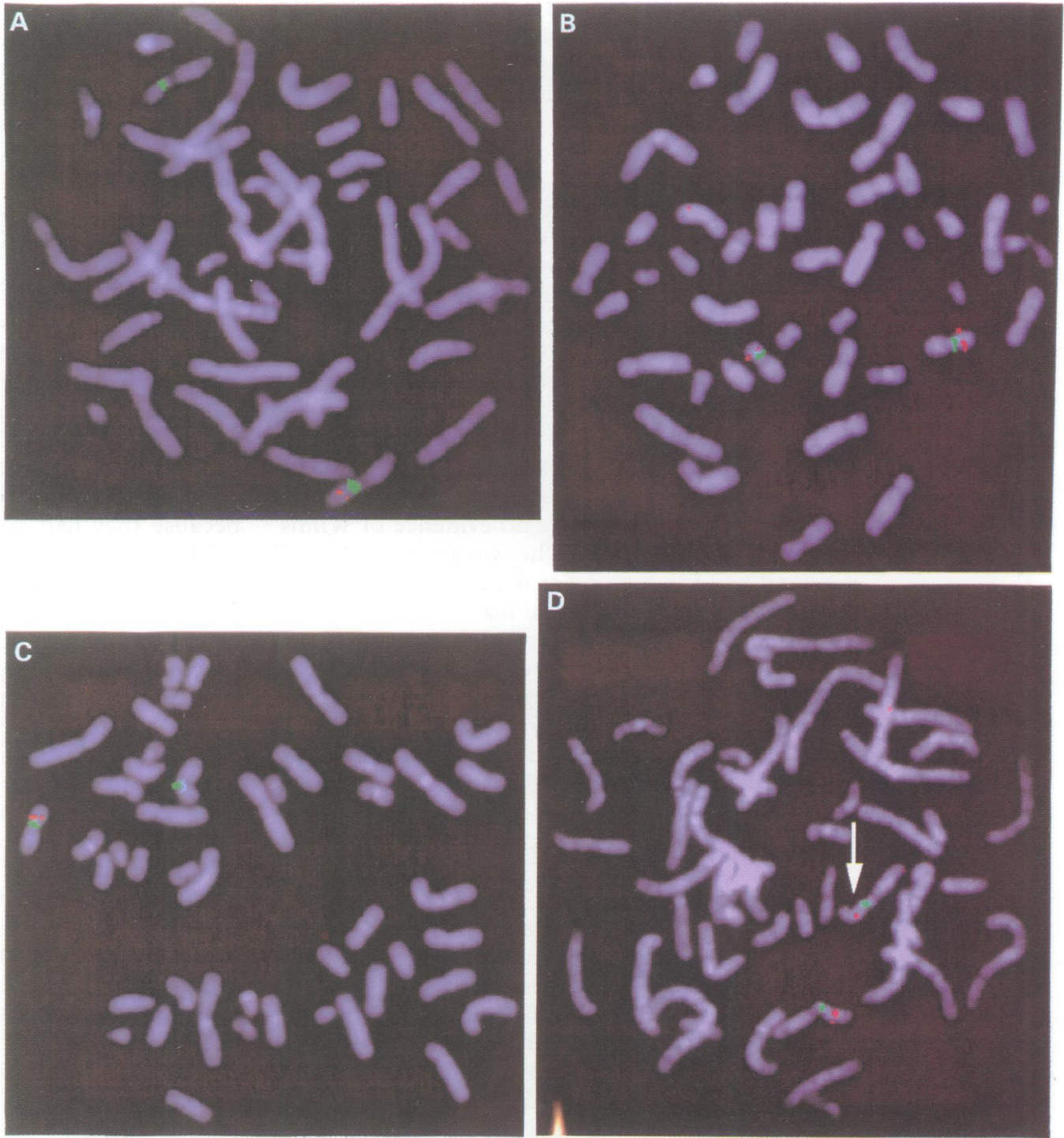

Figure 2 In all cells shown the 11 homologues are identified by the green (FITC) signal from the alphoid centromere specific probe, D11Z1. The sites of cosmid hybridisation are labelled in red (rhodamine). (A) FISH result from case 13. The FAT5 (PAX6) cosmid signal is present only on the normal homologue. (B) FISH result from case 13. The B2.1 (WT1) cosmid signal can be seen on both 11 homologues showing that this patient is not deleted at this locus. (C) $A$ representative FISH result from case 16. The p60 (D11S324) cosmid signal is seen on only one of the two 11 homologues. This patient's submicroscopic deletion included the three other cosmids used, FO2121, FAT5, and B2.1. (D) FISH result from case 19 following hybridisation with cosmid FAT5. The red cosmid signal seen on the partially deleted chromosome 11 (arrowed) was consistently smaller than that seen on the normal homologue (see text).

G453, ${ }^{13}$ which is approximately $25-30 \mathrm{~kb}$ distal to PAX6.

CASES $2-10$

Ages ranged from 7 months to 7 years 4 months when referred for FISH studies. All had sporadic, isolated aniridia, normal karyotypes, and were not deleted for the four cosmids used.

CASE 11

He was referred at 5 years of age and was originally ascertained with isolated bilateral aniridia, glaucoma, and learning difficulties. $\mathrm{He}$ had a normal karyotype and was not deleted for the four FISH probes used.

CASE 12

Recruited into the study at the age of 14 months, this male presented with aniridia, glaucoma, hypospadias, Fallot's tetralogy, hypoplastic first left rib, and absent first right rib.
His mother has a bilateral anterior chamber defect which was thought to be a mild form of aniridia. The proband's conventional and molecular cytogenetic results, including those for the 22q11 DiGeorge critical region and $11 \mathrm{p} 13$ WAGR cosmids, were normal.

\section{CASE 13}

He presented at 8 months of age with isolated bilateral aniridia and optic atrophy. At that time ultrasound examination showed no evidence of renal tumours or genital anomalies, and all developmental milestones were normal. At 14 months, however, he exhibited a moderate degree of both developmental and growth delay. Both parents have normal vision. Conventional cytogenetic analysis in the proband showed an interstitial deletion in one chromosome 11 extending from p13-p15.1. The parental karyotypes were normal. In situ hybridisation with the WAGR region cosmids showed that the most proximal cosmids B2.1 
(WT1) (fig 2B) and D11S324 were present on both the normal and del(11), but that the distal cosmids FAT5 (PAX6) (fig 2A) and FO2121 were deleted in the abnormal chromosome.

\section{CASE 14}

This male was the third child born after an uneventful pregnancy at 36 weeks with a birth weight of $2300 \mathrm{~g}$ and at birth was noted to have undescended testes and mild hypospadias. However, following conventional cytogenetic studies which showed an interstitial 11p13p14.2 deletion, examination by a paediatric ophthalmologist found that he had bilateral aniridia. At 3 months, ultrasound examination showed that he only had one kidney (the left). At that time his left testis was palpable in the scrotum and there was no evidence of Wilms' tumour. At 9 months he was progressing well and was functioning at the bottom of the normal range. At that time he was also noted to have mild bilateral microphthalmia, deep set eyes, bilateral low set ears with rather overfolded helices, but still no evidence of Wilms' tumour. FISH studies with the WAGR cosmids showed that all four loci defined by the probes used were deleted in the abnormal chromosome 11 . The parental karyotypes were both normal.

CASE 15

A female was noted shortly after birth to have bilateral aniridia and has subsequently developed glaucoma. A renal scan at 3 months of age was normal, and physical examination at 5 months showed a rather unhappy child with a head circumference on the 50th centile and length on the 25th centile. She has small ears, micrognathia, and bilateral epicanthic folds, but no other dysmorphic features. Conventional cytogenetic studies showed an interstitial $11 \mathrm{p} 11.2-14.1$ deletion. The karyotypes of both parents were normal. FISH studies with the WAGR cosmids showed that the abnormal 11 homologue was deleted for all four WAGR cosmids.

CASE 16

A male was noted at birth to have bilateral aniridia and mild genital abnormalities. At 17 months of age he developed Wilms' tumour which was successfully resected. At $51 / 2$ years of age, he is developing normally. $\mathrm{He}$ has an apparently normal karyotype, but FISH studies showed a submicroscopic deletion encompassing all four of the cosmids examined (fig $2 \mathrm{C}$ ).

CASE 17

This was a familial isolated aniridia family with transmission from father to son (the proband) and no other known affected family members. Conventional and molecular cytogenetic results were both normal

CASE 18

This was a familial isolated aniridia family with affected subjects in three generations. Conventional and molecular cytogenetic results were both normal.
CASE 19

This was a familial isolated aniridia family with transmission from mother to daughter. Chromosomes in both patients were apparently normal, but FISH studies showed a partial deletion of FAT5 (PAX6) (fig 2D) and absence of the FO2121, C1170, and 3UT5 cosmids on one chromosome 11 indicating that the deletion extends approximately $245 \mathrm{~kb}$ distal from FAT5.

\section{Discussion}

The aim at the outset of this study was to determine the frequency of molecular cytogenetic deletions involving loci within the WAGR region in a series of patients ascertained with isolated sporadic or familial aniridia. However, additional patients were also studied either because they had aniridia in association with WAGR syndrome or other malformations, or cytogenetically visible interstitial $11 \mathrm{p}$ deletions in which FISH studies were used to define the extent and hence significance of the deletion within the WAGR region. The 19 patients are considered by phenotypic group.

The first contained 13 patients with isolated sporadic or familial aniridia, and using a combination of both conventional and molecular cytogenetic techniques, two cases (one sporadic and one familial) were found to be abnormal. The first, case 1 , has an apparently balanced $t(7 ; 11)$ and in our previous report ${ }^{16}$ we suggested that this patient's aniridia was the result of a position effect caused by the translocation breakpoint disrupting the chromatin domain distal to PAX6. Such an effect had been reported in patients SIMO and SGL by Fantes et al. ${ }^{15}$ Our recent FISH studies in case 1 show that the $11 \mathrm{p} 13$ breakpoint is approximately $25-30 \mathrm{~kb}$ distal to the $3^{\prime}$ end of the PAX6 gene, occurring within the region defined by cosmid G453.

The second patient, case 19, part of a familial aniridia pedigree, was found to have a submicroscopic deletion involving the distal part of the FAT5 cosmid (fig 2D) and extending distally for $\sim 245 \mathrm{~kb}$. Further studies are in progress to determine whether PAX6 has been disrupted by this deletion. However, this result offers clinical reassurance by showing that the deletion does not extend proximally to WT1, and is similar to a previously reported case of familial aniridia. ${ }^{14}$ By contrast, a familial aniridia family with a deletion including PAX6 and WT1 was associated with isolated aniridia in the mother, but the identical deletion in her son produced aniridia, a horseshoe kidney, and Wilms' tumour. ${ }^{12}$

We detected one familial submicroscopic deletion among the $13(7.7 \%)$ cases of isolated aniridia (10 sporadic, three familial). Previous reports using either PFGE in combination with FISH, ${ }^{12-14}$ or quantitative Southern hybridisation combined with conventional cytogenetics, ${ }^{17}$ have identified seven deletions out of 42 patients who at the time of analysis were described as having isolated aniridia. Three of these deletions were cytogenetically visible and in each case the molecular studies confirmed the involvement of WT1. The remaining four 
deletions were submicroscopic, one of which included WT $1 .{ }^{12}$ All four of these reported submicroscopic deletions included the region covered by the cosmids used in this study and so would have been detected by our methods. Our lower detection rate for deletions among isolated aniridia patients probably reflects the ascertainment bias of the different studies, but if we combine these data, deletions have been detected in a total of eight out of $59(13.5 \%)$ isolated aniridia patients, five sporadic and three familial. As mentioned above, there have also been three reported cases of isolated aniridia (two familial and case 1) with apparent position effect breakpoints distal to and not including PAX6. ${ }^{15}{ }^{16}$ Overall, therefore, 11 out of $59(18.6 \%)$ of isolated aniridia cases have been reported with abnormalities which have been identified and characterised using molecular methods.

The second group consists of two patients with aniridia associated with one or more of the WAGR syndrome abnormalities, who were shown to be deleted at all four loci. The deletion in one (case 14) was cytogenetically visible but was submicroscopic in the other (case 16). Case 14 has developmental delay and genitourinary and renal anomalies in addition to his aniridia and, as he is deleted for all four cosmids, must be considered at high risk of developing renal tumours before the age of 7. ${ }^{18}$ Case 16 underlines the importance of screening all aniridia patients as early as possible. He presented with sporadic aniridia and mild genital anomalies and Wilms' tumour was subsequently discovered during a regular three monthly renal ultrasound examination. The tumour was successfully treated after which FISH studies showed that he had a submicroscopic deletion which included all four cosmids. He has no other significant clinical problems at the age of $51 / 2$ years. The genitourinary (GU) anomalies observed in these two males are not surprising as $30-50 \%$ of males with WAGR deletions have GU anomalies, including cryptorchidism and hypospadias, whereas GU anomalies in equivalent female patients are rarely observed.

The four patients comprising the third group all had aniridia but with clinical features other than those of the WAGR syndrome. Cases 11 and 12 did not have deletions detectable with the cosmids used, but the possibility of a smaller deletion, particularly in PAX6, cannot be excluded by our test. Further molecular screening of these patients will be required to determine whether their aniridia is the result of an intragenic PAX6 mutation, and until these results are known we cannot be sure whether their other malformations are coincidental to their aniridia. In contrast to cases 11 and 12 , case 13 had a visible $11 \mathrm{p} 13 \mathrm{p} 15.1$ deletion, the proximal boundary of which was shown by FISH to lie between PAX6 and WT1 placing the breakpoint $\sim 500 \mathrm{~kb}$ distal to WT1. Cases with sporadic aniridia (KAZHM) ${ }^{13}$ and aniridia, retardation, and GU anomalies (ANS4), ${ }^{14}$ also with breakpoints $300-500 \mathrm{~kb}$ distal to WT1, have been reported, and as WT1 is not deleted in these patients the results suggest that they fall within the low risk category for Wilms' tumour. However, as breakpoints 30-185 kb distal to PAX6 have been implicated in a position effect leading to the disruption of normal PAX6 function, it may be prudent to question whether breakpoints $300-500 \mathrm{~kb}$ distal to WT1 may also in some way alter normal WT1 expression, thereby causing an increased Wilms' tumour risk in these exceptional patients. However, too few cases with similar breakpoints have been reported and followed up to assess this possibility, and in the meantime regular renal ultrasound monitoring is being continued in case 13 . The cytogenetically visible deletion in case 15 was shown by FISH to include all four cosmid loci. At the time of writing this female infant is 3 months old and, apart from relatively minor facial dysmorphism, only has bilateral aniridia, and the deletion of WT1 places her at high risk of developing renal tumours.

By combining the results presented in this study with published reports, it is clear that FISH, either alone or in combination with other molecular approaches, can differentiate between deletions in the WAGR region which include WT1 and those which do not, thereby identifying patients with high and low renal tumour risks respectively. To date, out of 25 patients reported with isolated or multiple malformations together with cytogenetically visible interstitial $11 \mathrm{p}$ deletions involving $11 \mathrm{p} 13$, two ( $8 \%$ ) have been shown by molecular techniques to have proximal breakpoints which are distal to and therefore not directly involving WT1 (case 13, ANS $4^{14}$ ). Neither of these patients at the time of reporting had Wilms' tumour. Of the remaining 23 cases, 10 had aniridia and Wilms' tumour, 10 had aniridia with other WAGR anomalies excluding Wilms' tumour, and three had isolated aniridia. More significantly nine submicroscopic deletions have been reported, six of which included PAX6 and WT1, and five of these patients have aniridia and Wilms' tumour, while the remaining case was ascertained with isolated sporadic aniridia (MAFRA). ${ }^{13}$ The three remaining submicroscopic deletions did not include WT1. Furthermore, molecular studies have also been used to identify the extent of WAGR gene deletions in patients with aniridia and a variety of complex unbalanced structural chromosome rearrangements involving $11 \mathrm{p} 13$. Five of such cases reported to date were shown to be deleted for all the WAGR loci tested in this study, ${ }^{17}$ whereas the $11 \mathrm{p} 13$ breakpoint in another case (DG85) ${ }^{13}$ did not involve WT1.

These combined results illustrate the resolving power of a variety of molecular techniques for defining the extent of WAGR region deletions in patients presenting with either isolated aniridia or in association with other WAGR anomalies. Our results using FISH together with prudently selected probes show that this approach is sufficient to identify and define the extent of both visible and submicroscopic deletions, thereby providing clinical geneticists with essential prognostic information with respect to the risk of Wilms' 
tumour onset. Clearly, high resolution molecular techniques such as PFGE are still essential for the detailed refinement of deletion breakpoints, but as successful treatment for Wilms' tumour is strongly correlated with early diagnosis, it is clear that the results presented in this and previous reports indicate that rapid FISH studies should be performed on all aniridia patients as soon after diagnosis as is practicable.

The authors gratefully acknowledge the many clinicians who have contributed patients to this study. The in situ analysis was have contributed patients to this study. The in situ analysis was carried out with equipment purchased with the financial
support of the Wellcome Trust. Veronica van Heyningen is a support of the Wellcome Trust. Veronica van Heyningen is a Howard Hughes International Research Scholar. We are also
grateful to Mr John Barber and Professor P Jacobs for construcgrateful to Mr John Barber and Professor P Jacobs for constructive criticism of the manuscript and to $\mathrm{Dr} \mathrm{H}$ Willard for the gift
of the pLC11A (D11Z1) 11 centromere alphoid repeat probe.

1 Francke U, Holmes LB, Atkins L, Riccardi VM. AniridiaWilms' tumor association: evidence for specific deletion of 11p13. Cytogenet Cell Genet 1979;24:185-92.

2 Riccardi VM, Sujansky E, Smith AC, Francke U. Chromosomal imbalance in the aniridia-Wilms' tumor association: somal imbalance in the aniridia-Wilms' tumor assocition

3 Turleau C, de Grouchy J, Nihoul-Fekete C, Dufier JL, Chavin-Colin F, Junien C. Del 11p13/nephroblastoma without aniridia. Hum Genet 1984;67:455-6.

4 Narahara K, Kikkawa K, Kimira S, et al. Regional mapping of catalase and Wilms tumor-aniridia, genitourinary abnormalities, and mental retardation triad loci to the chromosome segment 11p1305p1306. Hum Genet 1984; 66:181-5.

5 Moore JW, Hyman S, Antonarakis SE, Mules EH, Thomas GH. Familial isolated aniridia associated with a translocation involving chromosomes 11 and 22 [t(11;22)(p13; q12.2)]. Hum Genet 1986;72:297-302.
6 Call KM, Glaser T, Ito CY, et al. Isolation and characterization of a zinc finger polypeptide gene at the human chromosome 11 Wilms' tumor locus. Cell 1990;60:509-20.

7 Gessler M, Poustka A, Cavanee W, Neve RL, Orkin SH, Bruns GAP. Homezyous deletion in Wilms tumours of Bruns GAP. Homozygous deletion in Wilms tumours of 1990;343:774-8.

8 Ton CCT, Hirvonen $\mathrm{H}$, Miwa $\mathrm{H}$, et al. Positional cloning and characterization of a paired box- and homeoboxcontaining gene from the aniridia region. Cell 1991;67 1059-74.

9 Jordan T, Hanson I, Zaletayev D, et al. The human PAX6 gene is mutated in two patients with aniridia. Nat Genet 1992;1:328-32.

10 Glaser T, Walton DS, Maas RL. Genomic structure, evolutionary conservation and aniridia mutations in the human PAX6 gene. Nat Genet 1992;2:232-9.

11 Hanson IM, Seawright A, Hardman $\mathrm{K}$, et al. PAX6 mutations in aniridia. Hum Mol Genet 1993;2:915-20.

12 Fantes JA, Bickmore WA, Fletcher JM, Ballesta F, Hanson IM, van Heyningen V. Submicroscopic deletions at the WAGR locus, revealed by nonradioactive in situ hybridization. Am f Hum Genet 1992;51:1286-94.

13 Fantes JA, Oghene K, Boyle S, et al. A high-resolution integrated physical, cytogenetic, and genetic map of human chromosome 11: distal p13 to proximal p15.1. Genomics 1995;25:447-61.

14 Dreschler M, Meijers-Heijboer EJ, Schneider S, et al. Molecular analysis of aniridia patients for deletions involving the Wilms' tumor gene. Hum Genet 1994;94:331-8.

15 Fantes J, Redeker B, Breen M, et al. Aniridia-associated cytogenetic rearrangements suggest that a position effect may cause the mutant phenotype. Hum Mol Genet 1995;4: 415-22.

16 Crolla JA, Cross I, Atkey N, Wright M, Oley CA. FISH studies in a patient with sporadic aniridia and $t(7$ 11)(q31.2;p13). F Med Genet 1996;33:66-8.

17 Mannens M, Hoovers JMN, Bleeker-Wagemakers EM, et al. The distal region of $11 \mathrm{p} 13$ and associated genetic diseases. Genomics 1991;11:284-93.

18 Breslow NE, Beckwith JB, Ciol M, Sharples K. Age distribution of Wilms' tumor: report from the national Wilms' tumor study. Cancer Res 1988;48:1653-7.

19 Mitelman F, ed. ISCN (1995). An international system for human cytogenetic nomenclature. Basel: Karger, 1995. 